08

\title{
Синтез сложных оксидов со структурой граната методом распылительной сушки водного раствора солей
}

\author{
() А.В. Макеенко, Т.В. Ларионова, О.Г. Климова-Корсмик, Р.В. Старых, \\ В.В. Галкин, О.В. Толочко
}

Санкт-Петербургский политехнический университет Петра Великого, 195251 Санкт-Петербург, Россия

e-mail: amakeenko@list.ru

(Поступило в Редакцию 29 июня 2016 г.)

Показана возможность применения метода распылительной сушки для получения порошков сложных оксидов со структурой граната. Методами ДТА, ТГА, РФС, РСА исследованы процессы, происходящие при нагреве синтезированного оксидно-солевого продукта, приводящие к формированию материала со структурой граната. Продемонстрирована возможность синтеза однофазной структуры граната системы $\left(\mathrm{Y}_{x} \mathrm{Gd}_{(3-x)}\right)_{3} \mathrm{Al}_{5} \mathrm{O}_{12}$ во всем диапазоне составов.

DOI: 10.21883/JTF.2017.04.44321.1960

\section{Введение}

Соединения со структурой граната с общей формулой $\mathrm{R}_{3} \mathrm{Me}_{5} \mathrm{O}_{12}$ применяются в промышленной и медицинской томографии, изготовлении активного тела лазеров, радиометрии [1,2]. Наиболее изученным материалом являются кристаллы на основе алюмоиттриевых гранатов - $\mathrm{Y}_{3} \mathrm{~A}_{5} \mathrm{O}_{12}$ (YAG) [3-5]. Эти соединения, активированные ионами редкоземельных элементов $\mathrm{Nd}^{3+}$, $\mathrm{Ce}^{3+}, \mathrm{Gd}^{3+}$, широко применяются в лазерной оптике и электронике $[6,7]$ и перспективны для производства светоизлучающих диодов белого свечения $[8,9]$.

Сцинтилляционные материалы на основе гранатов могут изготавливаться в форме монокристаллов и оптических керамик $[7,10]$. Классическими методами получения материалов со структурой граната являются выращивания монокристаллов из расплава, раствора и газовой среды [11]. Эти методы являются трудоемкими и зачастую не могут обеспечить требуемой однородности состава. Альтернативным вариантом получения материалов со структурой граната является изготовление оптических керамик, где в качестве исходного сырья требуется наличие порошков высокой чистоты. Преимушественно для получения порошков сложных оксидов используют метод твердофазного синтеза [3], основным недостатком которого является загрязнение порошка в результате взаимодействия с мелющими телами. Золь-гель метод позволяет получать материал высокой чистоты и однородности химического состава $[8,11]$, но крайне длителен и имеет низкий выход конечного продукта. Метод распылительной сушки водных растворов солей с последующим отжигом позволяет получать тонкодисперсные порошки оксидов высокой чистоты с производительностью до $100 \mathrm{~g} / \mathrm{h}$, что делает его перспективным для производства подобных материалов.

В настоящей работе рассмотрена возможность применения метода распылительной сушки для получения порошков со структурой граната на примере системы $(\mathrm{Gd}, \mathrm{Y})_{3} \mathrm{Al}_{5} \mathrm{O}_{12}: \mathrm{Ce}$.

\section{1. Материалы и методика эксперимента}

В качестве исходных материалов были использованы нитрат гадолиния гексагидрат $\mathrm{Gd}\left(\mathrm{NO}_{3}\right)_{3}^{*} 6 \mathrm{H}_{2} \mathrm{O}$ марки $\mathrm{XЧ,} \mathrm{нитрат} \mathrm{алюминия} \mathrm{нонагидрат} \mathrm{Al}\left(\mathrm{NO}_{3}\right)_{3} 9 \mathrm{H}_{2} \mathrm{O}$ марки ХЧ, оксид иттрия $\mathrm{Y}_{2} \mathrm{O}_{3}$ марки ХЧ, который был предварительно растворен в концентрированной азотной кислоте $(56.2 \%)$ марки ОСЧ, и нитрат церия гексагидрат $\mathrm{Ce}\left(\mathrm{NO}_{3}\right)_{3}^{*} 6 \mathrm{H}_{2} \mathrm{O}$ марки ОСЧ. В качестве поверхностно активных веществ (ПАВ) использовались лимонная кислота марки ОСЧ и этиленгликоль марки ТЕХ.

Порошки синтезировались методом распылительной сушки водного раствора нитратов на установке Buchi Spray DryerB-290. Исходные нитраты алюминия, иттрия, гадолиния и церия были тщательно взвешены, исходя из стехиометрического соотношения этих элементов в заданной композиции синтезируемого сложного оксида: $\mathrm{Y}_{x} \mathrm{Gd}_{(3-x)} \mathrm{Al}_{5} \mathrm{O}_{12}: \mathrm{Ce} \mathrm{Al}: \mathrm{Gd}: \mathrm{Y}: \mathrm{Ce}=5:(3-X): X: 0.004$, а затем растворены в дистиллированной воде для получения 5\% раствора, после этого в раствор добавляли ПАВ в количестве $3 \mathrm{~g}$ на $100 \mathrm{ml}$ воды в соотношении этиленгликоль: лимонная кислота $2: 1$. Приготовленный таким образом раствор подавался через распылительное сопло установки в сушильную камеру, где смешивался с потоком горячего воздуха. При сушке в потоке воздуха происходило полное или частичное разложение солей с образованием сухого оксидно-солевого продукта, который скапливался в коллекторе установки. Температура на выходе не превышала $200^{\circ} \mathrm{C}$. После синтеза полученный порошок подвергался отжигу в воздушной атмосфере в интервале температур $300-1600^{\circ} \mathrm{C}$.

Синтезированные порошки были исследованы методами термогравиметрического (ТГА) и дифференциально- 

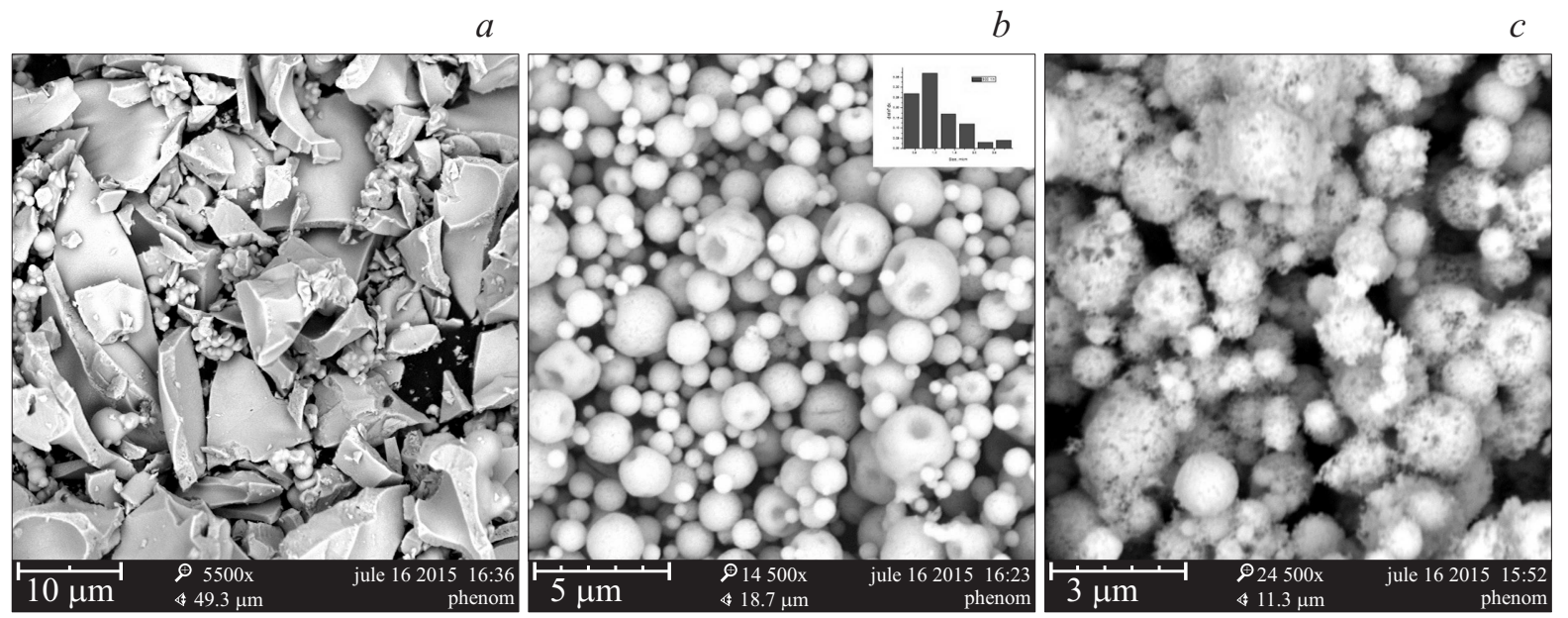

Рис. 1. Микрофотографии порошков, синтезированных без использования ПАВ и отожженных при $T=600^{\circ} \mathrm{C}$ в течение $1 \mathrm{~h}(a)$, синтезированных с использованием ПАВ и отожженных при $T=600^{\circ} \mathrm{C}$ в течение $1 \mathrm{~h}(b)$ и при $T=1050^{\circ} \mathrm{C}$ в течение $3 \mathrm{~h}(c)$.
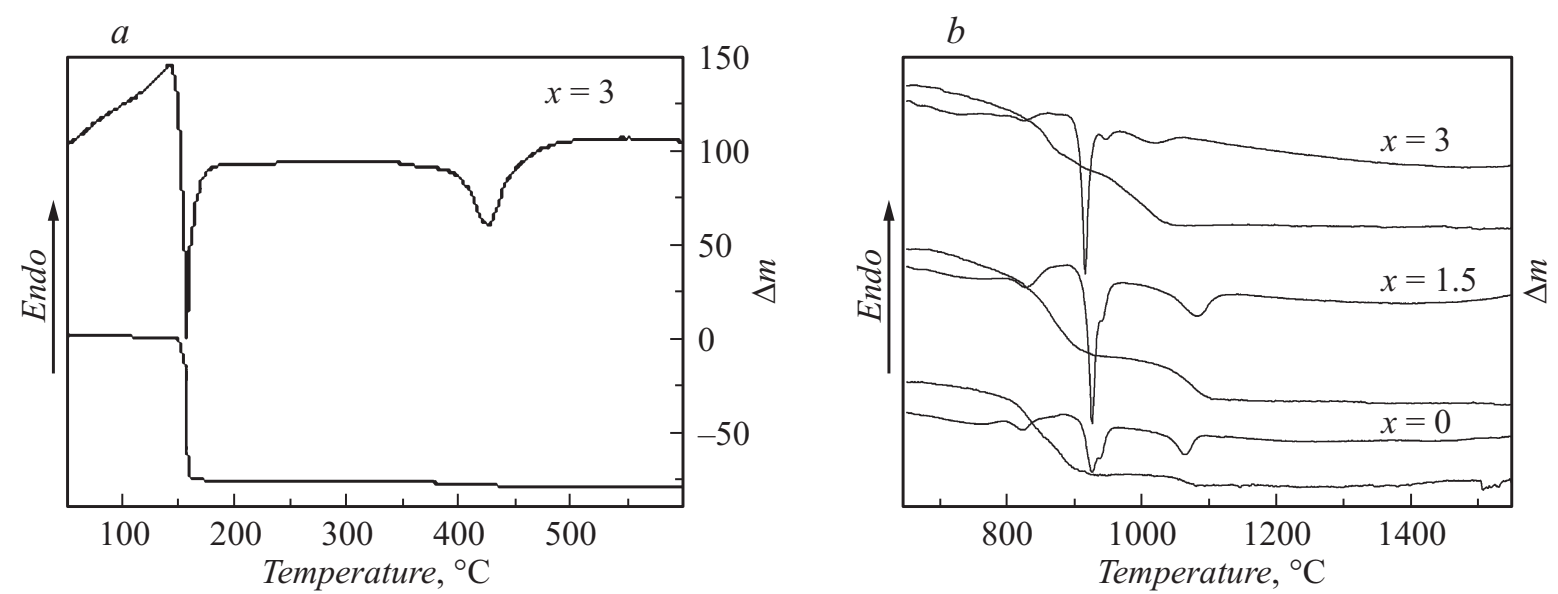

Рис. 2. ДТА и ТГА кривые, полученные при нагревании порошка $\left(\mathrm{Y}_{x}, \mathrm{Gd}_{(3-x)}\right) 3 \mathrm{Al}_{5} \mathrm{O}_{12}$ непосредственно после синтеза $(a)$ и после предварительного отжига при $T=600^{\circ} \mathrm{C}$ в течение $1 \mathrm{~h}(b)$.

Таблица 1. Результаты ТГА и ДТА для $\mathrm{Y}_{3} \mathrm{Al}_{5} \mathrm{O}_{12}$

\begin{tabular}{|c|c|c|c|}
\hline $\begin{array}{c}\text { Температурный } \\
\text { диапазон, }{ }^{\circ} \mathrm{C}\end{array}$ & $\begin{array}{c}\text { Потеря } \\
\text { массы, \% }\end{array}$ & $\begin{array}{c}\text { Тепловой } \\
\text { эффект, } \mu \mathrm{W} / \mathrm{mg}\end{array}$ & Процесс \\
\hline $140-200$ & 72 & -17 & $\begin{array}{c}\text { Разложение нитратов (приведена реакция } \\
\text { на примере нитрата алюминия) } \\
2 \mathrm{Al}\left(\mathrm{NO}_{3}\right)_{3}{ }^{*} 9 \mathrm{H}_{2} \mathrm{O} \rightarrow 2 \mathrm{Al}(\mathrm{OH})_{3}+6 \mathrm{NO}_{2} \uparrow+9 \mathrm{H}_{2} \mathrm{O} \uparrow\end{array}$ \\
\hline $350-460$ & 9 & -27 & $\begin{array}{c}\text { Образование аморфного оксида (приведена } \\
\text { реакция на примере оксида алюминия) } \\
2 \mathrm{Al}(\mathrm{OH})_{3} \rightarrow \mathrm{Al}_{2} \mathrm{O}_{3}+3 \mathrm{H}_{2} \mathrm{O} \uparrow\end{array}$ \\
\hline $800-852$ & $1-3 \%$ & -0.29 & \\
\hline $900-970$ & $0 \%$ & -0.5 & $\begin{array}{c}\text { Кристаллизация двуфазной структуры - } \\
\text { гранат }(\mathrm{Y}, \mathrm{Gd})_{3} \mathrm{Al}_{5} \mathrm{O}_{12} \text { и перовскит } \\
(\mathrm{Y}, \mathrm{Gd}) \mathrm{AlO}_{3}\end{array}$ \\
\hline $970-1150$ & $1-3 \%$ & -0.36 & $\begin{array}{c}\text { Образование однофазной структуры } \\
\text { граната }(\mathrm{Y}, \mathrm{Gd})_{3} \mathrm{Al}_{5} \mathrm{O}_{12}\end{array}$ \\
\hline
\end{tabular}


Таблица 2. Химический состав $\mathrm{Y}_{3} \mathrm{Al}_{5} \mathrm{O}_{12}$ на основании данных РФС

\begin{tabular}{l|c|c|c|c|c}
\hline Образец & $\mathrm{O}(\mathrm{O} 1 s)$ & $\mathrm{C}(\mathrm{C} 1 s)$ & $\mathrm{Y}+\mathrm{Ce}$ & $\mathrm{Al}$ & $\mathrm{N}$ \\
\hline $\begin{array}{l}\text { Исходный порошок } \\
\text { (после синтеза) }\end{array}$ & $35^{*}$ & 54 & 3 & 5 & $4^{*}$ \\
\hline $\begin{array}{l}\text { После отжига при } \\
T=300^{\circ} \mathrm{C}, t=1 \mathrm{~h}\end{array}$ & 35 & 55 & 4 & 6 & - \\
\hline $\begin{array}{l}\text { После отжига при } \\
T=600^{\circ} \mathrm{C}, t=1 \mathrm{~h}\end{array}$ & 38 & 39 & 10 & 15 & - \\
\hline $\begin{array}{l}\text { После отжига при } \\
T=1050^{\circ} \mathrm{C}, t=1 \mathrm{~h}\end{array}$ & 45 & 23 & 12 & 20 & -
\end{tabular}

Примечание. * Вероятно, для исходного порошка содержание О и $\mathrm{N}$ по результатам РФС является несколько заниженным по сравнению с фактическим, так как анализ проходит в условиях высокого вакуума, что может привести к удалению летучих компонентов.

термического анализа (ДТА) на установке SETSYS Evo-1750 SETARAM при нагреве до $1600^{\circ} \mathrm{C}$ со скоростью $15 \mathrm{ged} / \mathrm{min}$ град/мин в аргоно-кислородной атмосфере в соотношении 5/1, расход газа контролировался в течение всего эксперимента и составлял $32 \mathrm{ml} / \mathrm{min}$ $\operatorname{Ar}$ и $8 \mathrm{ml} / \mathrm{min} \mathrm{O}_{2}$. Микроскопические исследования проводились на сканирующем электронном микроскопе PhenomProX. Фазовый состав исследовался методом рентгеноструктурного анализа (РСА) на дифрактометре D8 Advance Bruker в $\mathrm{CuK} \alpha$ монохроматизированном излучении. Химический состав контролировался методом рентгеновской фотоэлектронной спектроскопии (РФС) на Thermoscientific $\mathrm{K}$ alpha при использовании Al-излучения. Измерение спектров люминесценции производилось в геометрии „на отражение“ при непрерывном рентгеновском $(40 \mathrm{kV}, 10 \mathrm{~mA})$ возбуждении. Регистрирующая часть содержала монохроматор МДР-2 и фотоприемник ФЭУ-106. Полученные спектры корректировались

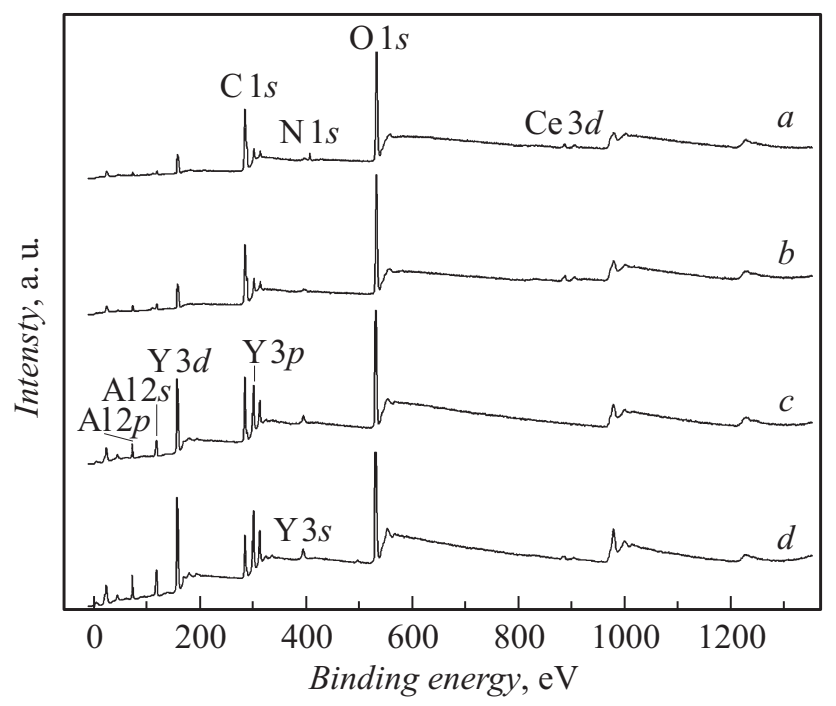

Рис. 3. Обзорные РФС спектры порошка $\mathrm{Y}_{3} \mathrm{Al}_{5} \mathrm{O}_{12}$ непосредственно после синтеза $(a)$ и после отжигов при $T=300(b)$, $T=600(c)$ и $T=1050^{\circ} \mathrm{C}(d)$. с учетом чувствительности ФЭУ и коэффициента пропускания монохроматора для различных длин волн.

\section{2. Результаты экспериментов}

На рис. 1 представлены микрофотографии частиц, синтезированных без и с применением ПАВ и отожженных при разных температурах (непосредственно после распылительной сушки оксидно-солевой порошок является гидрофильным, вследствие чего на открытом воздухе его частицы теряют форму, поэтому на фотографиях представлен порошок уже после отжига). Частицы, синтезированные без добавления ПАВ, слипаются, имеют нечеткие очертания и после отжига приобретают осколчатую форму (рис. 1, $a$ ). Добавление ПАВ приводит к образованию сферических частиц размером не более $3 \mu \mathrm{m}$, отжиг при $T=600^{\circ} \mathrm{C}$ приводит к некоторому уменьшению размеров частиц по сравнению с исходными, они становятся пористыми, сохраняя при этом исходную форму. После отжига при $T=1050^{\circ} \mathrm{C}$ частицы начинают распадаться, представляя собой уже, скорее, агломераты гораздо более мелких частиц, хотя очертания сферической формы исходных частиц хорошо прослеживаются.

ТГА и ДТА кривые, полученные при нагревании синтезированного порошка, представлены на рис. 2, $a$. В процессе нагрева потеря массы происходит в несколько этапов в связи с испарением остаточной влаги, кристаллизационной воды, разложением нитратов, выгоранием органических ПАВ и пр. и составляет в общей сложности около $80 \%$ от первоначальной массы. ДТА кривая представляет собой суперпозицию нескольких экзо- и эндотермических максимумов. При нагреве до температуры $150^{\circ} \mathrm{C}$ происходит резкий экзотермический процесс, связанный с самой значительной потерей массы пробы - более 70\%. Далее в интервале $350-500^{\circ} \mathrm{C}$ наблюдается несколько экзоэффектов, сопровождающихся небольшой потерей массы.

Из-за малой массы оставшейся пробы высокотемпературные ТГА и ДТА эффекты выражены крайне незна- 

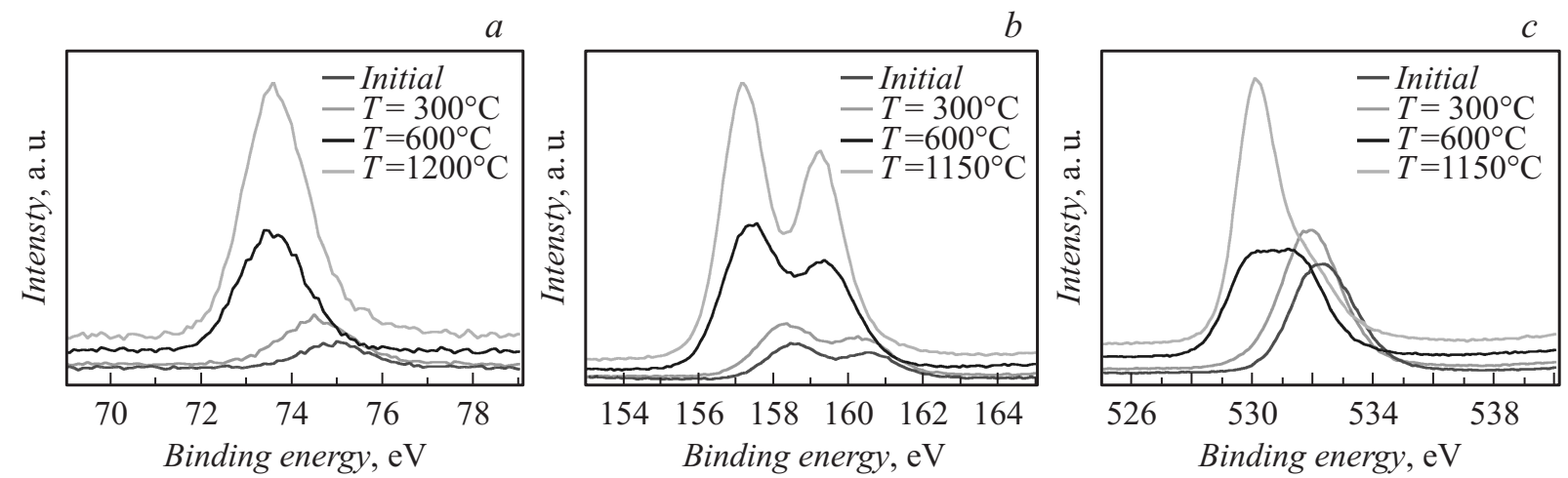

Рис. 4. РФС спектры остовных линий $\mathrm{A} 12 p(a), \mathrm{Y} 3 d(b), \mathrm{O} 1 s(c)$, синтезированных порошков в исходном состоянии и после отжигов при $T=300,600$ и $1050^{\circ} \mathrm{C}$.

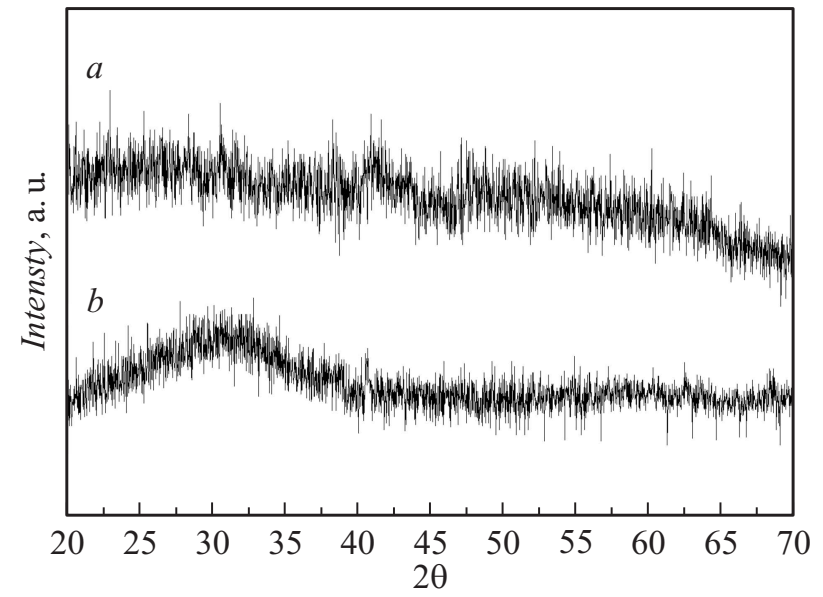

Рис. 5. Результаты РСА образца $\mathrm{Y}_{3} \mathrm{Al}_{5} \mathrm{O}_{12}$, отожженного при $T=300^{\circ} \mathrm{C}(a)$ и $600^{\circ} \mathrm{C}(b)$ в течение $1 \mathrm{~h}$.

чительно. Поэтому для исследования высокотемпературных процессов был проведен предварительный отжиг синтезированного порошка на воздухе при температуре $600^{\circ} \mathrm{C}$ в течение $1 \mathrm{~h}$, после чего оставшийся продукт был подвергнут повторному термическому анализу. Полученные ТГА и ДТА кривые приведены на рис. 2, $b$. На ДТА кривых предварительно отожженных порошков в температурном интервале $800-1150^{\circ} \mathrm{C}$ отмечается несколько экзотермических пиков, некоторые сопровождаются незначительной потерей массы. Результаты анализа представлены в табл. 1.

Для выяснения природы процессов, происходящих при нагреве, проведен анализ синтезированного порошка в исходном состоянии и после отжигов при $T=300,600$ и $1050^{\circ} \mathrm{C}$ РФС. Обзорные РФС спектры на примере $\mathrm{Y}_{3} \mathrm{Al}_{5} \mathrm{O}_{12}$ после синтеза и различных температур отжига приведены на рис. 3. Данные химического анализа представлены в табл. 2.

На рис. 4 приведены спектры остовных линий Al, Y и О. Увеличение интенсивности остовных пиков основных элементов в процессе обработки при аналогичных условиях съемки объясняется увеличением их доли от общей массы порошка. Незначительное количество азота наблюдалось только в исходном материале. Уже в результате первого отжига $\left(T=300^{\circ} \mathrm{C}\right)$ полностью исчезает азот. В результате второго $\left(T=600^{\circ} \mathrm{C}\right)$ уменьшается содержание углерода, интенсивности пиков элементов, входящих в состав граната, становятся выше. Помимо увеличения интенсивности пиков происходит сдвиг в сторону уменьшения энергии связи, что свидетельствует об изменении типа связи от ионного к ковалентному и соответствует образованию оксидов из нитратов и гидроксидов. На основании проведенного исследования можно предположить, что экзотермический эффект и потеря массы в температурном интервале $140-200^{\circ} \mathrm{C}$ обусловлены разложением нитратов с образованием гидроксидов, второй экзотермический пик соответствует образованию аморфного оксида из гидроксида.

Все синтезированные порошки в исходном состоянии и отожженные до температур, не превышающих $900^{\circ} \mathrm{C}$, являются рентгеноаморфными (рис. 5). Рентгенофазовый анализ образцов, отожженных при разных температурах, показал, что образование стабильной кри-

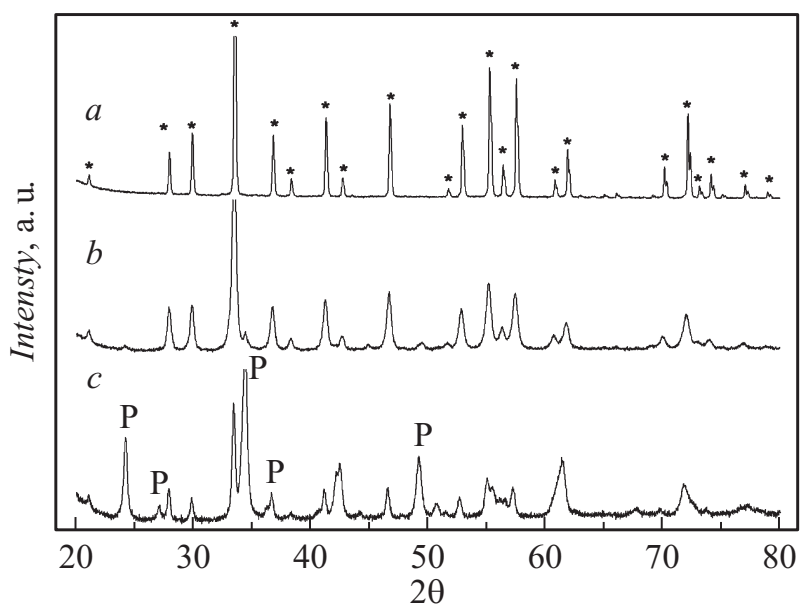

Рис. 6. Результаты РСА образцов $\left(\mathrm{Y}_{x}, \mathrm{Gd}_{(3-x)}\right)_{3} \mathrm{Al}_{5} \mathrm{O}_{12}$ при $x=3(a), 2.25(b), 0.75(c)$, отожженных при температуре $1050^{\circ} \mathrm{C}$ в течение 3 h. $P$ - перовскит, ${ }^{*}-$ гранат. 


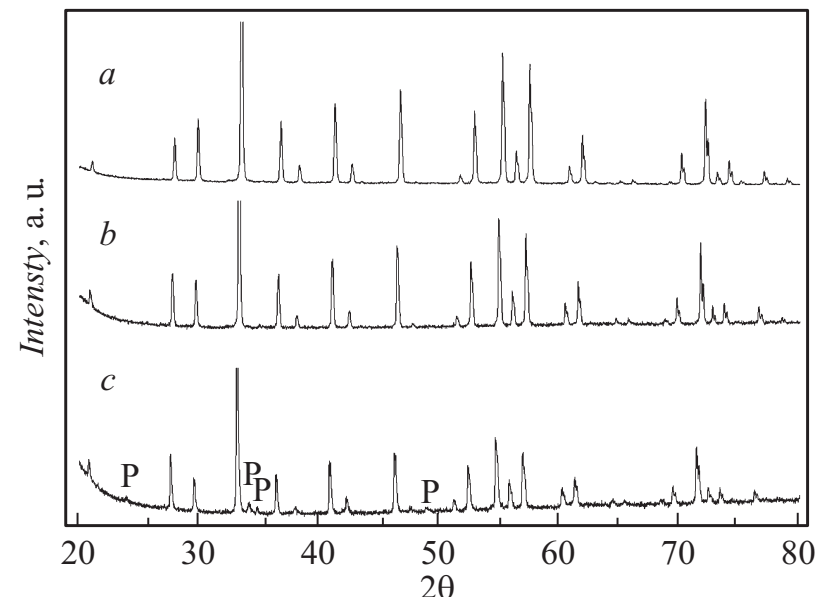

Рис. 7. Результаты РСА образцов $\left(\mathrm{Y}_{x}, \mathrm{Gd}_{(3-x)}\right)_{3} \mathrm{Al}_{5} \mathrm{O}_{12}$ при $x=3(a), 1.5(b), 0(c)$, отожженных при температуре $1600^{\circ} \mathrm{C}$. $P$ - перовскит, ${ }^{*}$ - гранат.

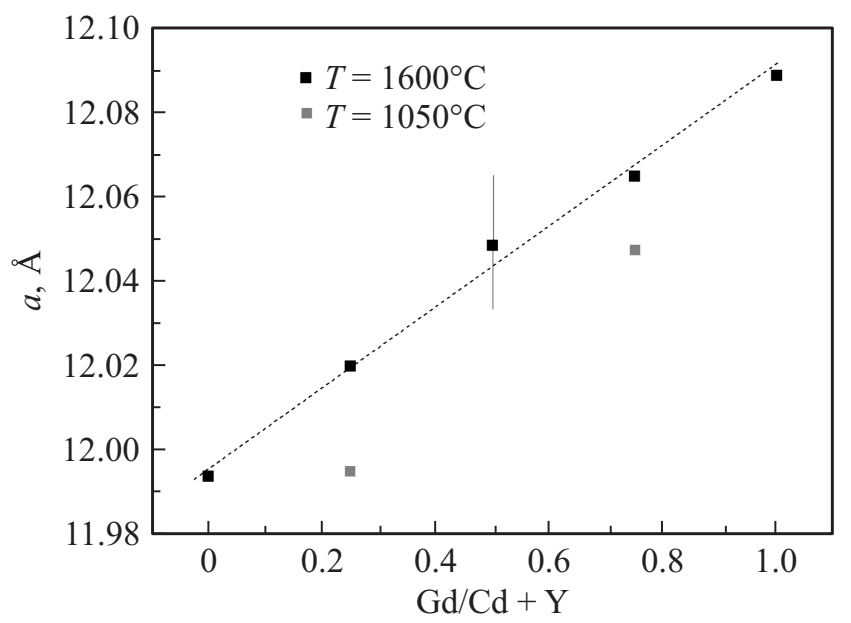

Рис. 8. Зависимость параметра кристаллической решетки граната от содержания гадолиния после отжига при $T=1050$ и $1600^{\circ} \mathrm{C}$.

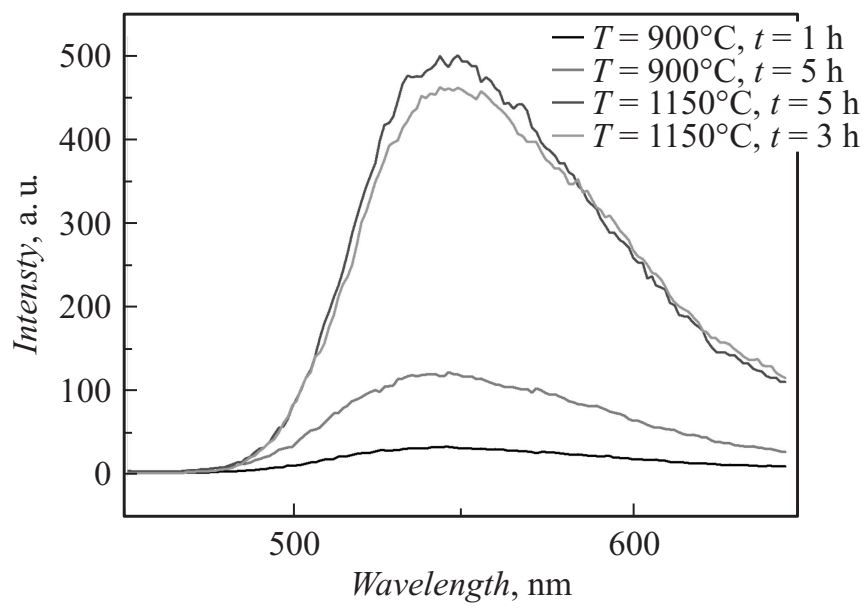

Рис. 9. Люминесцентные свойства порошков $\mathrm{Y}_{3} \mathrm{Al}_{5} \mathrm{O}_{12}$ в зависимости от температуры отжига. сталлической структуры проходит в несколько стадий. Процессу кристаллизации соответствует двойной экзотермический максимум, наблюдаемый на ДТА кривых в интервале $900-970^{\circ} \mathrm{C}$, этот эффект не сопровождается изменением массы, являясь следствием только структурных перестроек. Результаты РСА порошков с разным соотношением $\mathrm{Y}: \mathrm{Gd}$, отожженных при температуре $1050^{\circ} \mathrm{C}$, приведены на рис. 6. Во всех образцах была обнаружена фаза со структурой граната, однако при замене иттрия гадолинием в структуре появляется вторая кристаллическая фаза, идентифицированная как перовскит (YGd) $\mathrm{AlO}_{3}$, и ее содержание растет с увеличением доли Gd. Принимая во внимание, что увеличение доли гадолиния приводит также к снижению величины первого экзоэффекта и увеличению второго, можно предположить, что именно первый максимум отвечает за кристаллизацию граната, а второй является следствием кристаллизации перовскита.

Нагрев до более высоких температур $T=1600^{\circ} \mathrm{C}$ приводит к исчезновению фазы перовскита и образованию однофазной структуры граната практически для всех составов. Как видно из рентгенограмм, незначительное содержание перовскита было обнаружено только в образцах $\mathrm{Gd}_{3} \mathrm{Al}_{5} \mathrm{O}_{12}$ (рис. 7). Дифракционные пики становятся гораздо уже, что свидетельствует о более равновесной кристаллической структуре. Процессу образования однофазной структуры соответствует наиболее высокотемпературный экзотермический пик на ДТА кривых при температурах $970-1015^{\circ} \mathrm{C}$, который сопровождается небольшой потерей массы. Замена иттрия гадолинием приводит к увеличению параметра кристаллической ячейки граната, зависимость приведена на рис. 8. Интересно, что параметр ячейки увеличивается с увеличением температуры отжига, что, вероятно, связано с образованием однофазной структуры.

Полученные порошки обладают люминесцентными свойствами. Результаты измерений интенсивности $\mathrm{Y}_{3} \mathrm{Al}_{5} \mathrm{O}_{12}$ в зависимости от режима отжига представлены на рис. 9. Как и следовало ожидать, интенсивность возрастает при с увеличении температуры и времени отжига, что объясняется ростом содержания кристаллической фазы. При замене иттрия гадолинием происходит постепенное снижение интенсивности люминесценции и смещение максимума в длиноволновую область.

\section{Заключение}

Показана возможность получения субмикронных порошков сложных оксидов методом распылительной сушки водных растворов нитратов. Методами ДТА, ТГА, РФС, РСА исследованы процессы, происходящие при нагреве синтезированного оксидно-солевого продукта, приводящие к формированию материала со структурой граната. Продемонстрирована возможность синтеза однофазной структуры граната системы $\left(\mathrm{Y}_{x} \mathrm{Gd}_{(3-x)}\right)_{3} \mathrm{Al}_{5} \mathrm{O}_{12}$ во всем диапазоне составов. 


\section{Список литературы}

[1] Guo X., Sakurai K. // Jpn. J. Apl. Phys. 2000, Vol. 39, N 3. P. $1230-1234$.

[2] Globus M., Grinyov B. Inorganic scintillators for modern and traditional applications. Kharkiv, 2005. P. 583.

[3] Воробьева Р.3. // ФТП. 2012. Т. 46. № 4. С. 469-472.

[4] Petrenko O.A., Paul M.D., Ritter C., Zeiske T., Yethiraj M. // Physica B. 1999. Vol. 266. P. 41.

[5] Autrata R., Schauer P., Kvapil J., Kvapil J. // Phys. E. Sci. Instrum. 1978. Vol. 11. P. 707.

[6] Рандошкин В.В., Васильева Н.В., Колобанов В.Н., Михайлин В.В., Петровнин Н.Н., Спасский Д.А., Сысоев Н.Н. // Письма в ЖТФ. 2006. Т. 32. Вып. 5. С. 19.

[7] Добродей А.О., Подденежный Е.Н., Бойко А.А., Гришкова Е.И., Малашкевич Г.Е, Хотченкова Т.Г, Судник Л.В. Высокоплотная керамика и композиты на основе наноструктурированных порошков иттрий-алюминиевого граната. Актуальные проблемы физики твердого тела: сб. докл. Междунар. научн. конф. Минск. 2009. С. 187-189.

[8] Young C.J., Ravichandran D., Beomguist S.M., Morton D. // Appl. Phys. Lett. 2001. Vol. 78. N 24. P. 3800-3802.

[9] Андрийчук А.А., Волжсенская Л.Г., Захарко Л.М., Зоренко Ю.В. // ФТТ. 1987. Т. 29. Вып. 1. С. 232-235.

[10] Kanai T., Satoh M., Miura I. // J. Am. Ceram. Soc. 2008. Vol. 91. N 2. P. 456-462.

[11] Sarnchez R.D., Ramos C.A., Rivas J., Vaqueiro P., LorpezQuintela M.A. // Physica B. 2004. Vol. 354. P. 104-107. 